\title{
La concepción de derecho, moral y política en la Teoría de la Acción Comunicativa de Jürgen Habermas
}

Law, Moral and Politics in the Theory of Communicative Action of Jürgen Habermas

Jairo Miguel Torres-Oviedo

Universidad Cooperativa de Colombia-Colombia

Recibido: 2014-04-26

Envío a pares: 2014-04-26

Aprobado por pares: 2014-06-10

Aceptado: 2014-06-28

Pensamiento y Cultura | ISSN: 0123-0999 | eISSN: 2027-5331 pensam.cult | Vol. 17-1 | Junio de 2014 | pp. 113-137

DOI: 10.5294/pecu.2014.17.1.6 
La concepción de derecho, moral y política en la Teoría de la Acción Comunicativa de Jürgen Habermas

Resumen: El propósito de este artículo es realizar un análisis sistemático del proceso de institucionalización de la democracia, del Estado, la moral y el derecho en Occidente, a partir de los conceptos que Jürgen Habermas utiliza en la estructuración de su teoría de racionalidad comunicativa. Dichos planteamientos hacen parte de la Teoría de la acción comunicativa, expuesta en términos políticos y jurídicos de facticidad y validez.

Palabras clave: Derecho, racionalidad, política, comunicación.

\section{Law, Moral and Politics in the Theory of Communicative Action of Jürgen Habermas}

Abstract: The purpose of this paper is to perform a systematic analysis of the process of institutionalization of democracy, the state, morality and law in the West. Habermas concepts in his theory of communicative rationality are examined. Such approaches are part of the theory of communicative action and stated in political and legal terms as facticity and validity.

Key words: Law, rationality, politics, communication. 
El origen de este planteamiento se encuentra en Habermas cuando en su obra Teoría de la Acción Comunicativa, aparece una declaración acerca de su intención de construir a partir de los conceptos de racionalidad comunicativa y sociedad, una teoría de la modernidad que implemente las categorías implícitas en la praxis comunicativa cotidiana, desde las cuales se muestren discutan y solucionen distintas patologías sociales inherentes en los procesos de modernización social, en el marco de la acción discursiva generada por una "comunidad ideal de habla".

En torno a esta idea, Nelson Cuchumbé en su obra "Acción Comunicativa, Derecho y Organización Social y el Concepto de Derecho en Habermas", establece que "este planteamiento admite la asistencia a un momento histórico que supone, en primera instancia, la consolidación de un sujeto con capacidad de subjetividad" (Cachumbè 2004, 110) Es decir, un individuo que ha permitido la transformación del sujeto $y$ del ser del sujeto por sí mismo, una especie de autoconciencia, autorreflexión y autocercioramiento que se convierten en categorías fundamentales de la razón comunicativa. Capacidad que le ha permitido, construir de modo autónomo, una concepción individual y responsable sobre la mejor alternativa de vida, de mundo y de sociedad. De igual modo, también posibilita la consolidación como lo sostiene Habermas en su obra Facticidad y Validez:

"De un sujeto privado que también puede asumir los papeles de miembro de la sociedad civil, de ciudadano de un determinado Estado y de ciudadano del mundo. En su papel de ciudadano del mundo el individuo se funde en el hombre en general, es a la vez yo como particular y yo como universal". (Habermas 2008, 63)

En segunda instancia, esa capacidad subjetiva sostiene Cuchumbé:

"Facilita igualmente la constitución de las sociedades modernas a partir de unidades mínimas de acción, pero esta acción no es la del sujeto aislado, sino la de sujetos en comunicación, los que definen acciones mínimas y significativas, simbólicamente estructuradas. Es decir, al reconocimiento y ubicación de las relaciones interpersonales en 
el ámbito de los presupuestos normativos como las constituciones, las instituciones legales y propósitos comunes que hacen que el individuo articule su accionar a pautas que garantizan a todos los ciudadanos entenderse entre sí sobre los problemas que afrontan en el mundo actual, en la que el Estado opera como garante de los derechos comunes a todos los sujetos." (Cachumbè 2004, 6)

Lo anterior nos permite entender que el derecho también es un problema central de la "teoría de la acción comunicativa", al menos así lo hace aparecer Habermas cuando sostiene que "los supuestos básicos de la teoría de la acción comunicativa se ramifican también en diversos universos de discurso; y en tales universos han de poder acreditarse entrando en los contextos de argumentación que se desarrollan en estos" (Habermas 1987, 58), lo que implica que en el discurso práctico se usen criterios que rebasan el marco de la conciencia, pero que terminan en ella, son criterios sociales que se configuran lingüísticamente en los juegos de lenguaje y en los actos de habla. Y precisamente, estos son desarrollados en forma filosófico-política en el universo del discurso jurídico.

En este entramado teórico, el discurso jurídico se erige como una especie de mecanismo de apertura y cierres pivotantes entre sí montado en una estructura de un eje de giro común que comprende no sólo los atributos semánticos y sintácticos de las proposiciones, sino también los rasgos de sus emisiones, los adverbios utilizados y las representaciones internas de los emisores y receptores, los cuales posibilitan la formulación de enunciados performativos, es decir, locuciones que por el mismo hecho de ser nombradas se convierte en acción, como sostiene el mismo Austin "una clase especial de oraciones que se sirven no para hacer afirmaciones de la verdad o falsedad de una proposición sino para hacer algo" (Austin 1981, 23), esta proposición metalingüística sirve para volver explicita la fuerza ilocutiva del sujeto emisor.

Por tanto, la redefinición del concepto Derecho se hace necesaria introductoriamente en el ámbito del lenguaje, en consecuencia solo puede llamarse derecho legítimo aquel que surja de la formación discursiva de la opinión y la voluntad de ciudadanos dotados de unos mismos derechos. En esta medida, Habermas sostiene que: 
"La teoría discursiva del derecho explica la legitimidad del derecho con ayuda de procedimientos y presupuestos comunicativos institucionalizados a su vez jurídicamente que fundan la presunción de que los procesos de producción del derecho y aplicación del derecho conducen a resultados racionales." (Habermas 2008, 497)

El procedimiento consensual aquí determinado se fundamenta en la teoría de los actos de habla. Para Austin, citado en (Alexy 2012, 69), "los actos de habla son acciones que se realizan diciendo algo". Lo que permite en términos jurídicos, un uso público de la razón a partir de la cual se puedan intervenir en asuntos propios del ámbito discursivo del derecho, como por ejemplo, pretensiones de corrección normativa, como las disputas en torno a declaratorias de inexequibilidad de expresiones que no resisten los exámenes de constitucionalidad por poseer contenidos semánticos problemáticos con efectos discriminatorios o excluyentes.

Visto así las cosas, el derecho para Habermas se sustenta en las preferencias de los individuos idealmente racionales, las cuales pueden ser perfecta y consistentemente representadas por una clasificación de posibles resultados de interacción discursiva y voluntaria de ciudadanos dotados de unos mismos derechos y que tal interacción es la suma de las consecuencias de acciones individuales con pretensiones de validez en cada una de sus cuatro modalidades: inteligibilidad, verdad, sinceridad y corrección normativa.

Esta consideración es contraria a la explicada por Josep Aguiló en Teoría general de las fuentes del Derecho, cuando sostiene que "históricamente los doctrinantes han manifestado que el derecho tiene origen en la costumbre, la ley, la jurisprudencia, la misma doctrina e incluso, los principios generales del derecho" (Aguilò 2000, 6). Estas han sido y son consideradas fuentes formales del derecho.

Para Enrique Ghersi estas ideas se articulan en torno a dos tradiciones jurídicas tal como lo afirma en su ponencia "El Carácter Competitivo de las Fuentes del Derecho":

"Una primera tradición que tiene dos vertientes, el iusnaturalismo de origen religioso y el iusnaturalismo de origen racional. El primero supone que el Derecho es producto de la voluntad divina, 
que el Derecho es producto de Dios y que hay un orden en la creación divina que es el fundamento y el origen del orden jurídico, el orden jurídico no puede contradecir el orden de la creación divina. El segundo por su parte, considera que el Derecho se puede deducir racionalmente; que de la naturaleza del hombre uno puede deducir principios, por ejemplo, la libertad del hombre, la voluntad del hombre y a partir de esos principios generales deducir todo el sistema jurídico." (Ghersi 2007, 4)

Una segunda tradición es el positivismo jurídico, para este mismo autor:

"El término Derecho positivo viene del latín legimponeré que significa poner la ley, dictar la ley es una expresión latina. Curiosamente, hay algunos antecedentes en torno al término poneré o positum (que es el subjuntivo de poner en latín) en el Derecho Romano, pero el término se recién utiliza durante la Edad Media, es un término prácticamente desconocido en la antigüedad. En la antigüedad tardía hay una mención a iustitia positiva en el comentario de Calcidius al Timeo de Platón, que fue un comentario bastante difundido a finales de la antigüedad.

Hay un par de menciones a legemconderé y legemponeré; legemconderé es un sinónimo de legemponeré en el Digesto, que son mencionados por algunos autores como un antecedente meramente terminológico porque el concepto no se utilizaba. Es en 1140, Pedro Abelardo, el insigne teólogo francés, el que por primer vez utiliza de manera orgánica el término legimponeré y lo utiliza como sinónimo de Derecho producido por el hombre.

El término hace mucha fortuna, hasta el punto que legemponeré se convierte rápidamente en Derecho positivo, la idea de que el Derecho es dado por alguien, la idea de legemponeré implícitamente supone una definición de Derecho, que el Derecho lo pone algo, Derecho puesto por alguien, derecho positivo, derecho positum, es el Derecho puesto por alguien y supone una autoridad que pone el Derecho." (Ghersi 2007, 5-6) 
Lo que hace Habermas es tratar de romper con este paradigma general del derecho en el que su validez y legitimidad depende de la sujeción a unas normas organizadas lógicamente bajo el principio de no contradicción para el que la norma mayor no puede contradecir la norma menor, es un sistema que supone un origen monopólico del derecho. Del mismo modo considera que la derivación argumentativa del Derecho y la moral no son deductivas, sino que está sujeta a cánones de racionalidad diferente de tipo pragmático. Las instancias legislativas, escribe Habermas "son parte de un sistema de poder que tiene que estar legitimado en total si es que la legalidad pura ha de ser considerada signo de legitimidad" (Habermas 1995, 123). Bien es conocido que en un sistema democrático la sola legalidad no garantiza la lealtad de los ciudadanos. Para ello, se requiere que las normas legales gocen de validez y legitimidad, vale decir de reconocimiento y aceptabilidad; solo así, es posible garantizar un orden social regulado y cohesionado, que es una de las funciones del derecho en sociedades complejas y sistémicas; donde el derecho es un subsistema de poder, garante del orden y la regulación social. Es decir, desde la coerción y la sanción se busca establecer el orden.

Esta reconstrucción del Derecho escribe Habermas, "parte de los derechos que los ciudadanos han de reconocerse mutuamente si quieren regular legítimamente su convivencia con los medios del derecho positivo (Habermas 2008, 147). Y ese reconocimiento es posible a través de la puesta en práctica de una concepción de razón comunicativa; donde los ciudadanos puedan intersubjetivamente intercambiar sus concepciones del mundo y en medio de un contexto plural, construir los procesos de entendimiento que posibiliten el establecimiento de acuerdos válidos y legítimos para todos.

En este contexto, las fuentes del derecho aquí enunciadas desconocen factores y métodos que influyen de manera directa e indirecta en la creación, expresión y regulación práctica del derecho, tal es el caso de la desdoblada característica del lenguaje, es decir, entre lo locucionario y lo ilocucionario al igual que la conducta del individuo, sea esta racional o no, y la utilidad buscada por cada individuo para la satisfacción de sus necesidades tratadas en las teorías de la acción comunicativa. Lo paradójico de este asunto es el desconocimiento del carácter praxeológico 
del derecho y el rol de la conducta racional del individuo como un factor determinante y anterior a la elaboración de una norma o el reconocimiento de un derecho.

Por estos motivos, Habermas ha sostenido que el derecho moderno no puede patentar su legitimidad a partir del discurso práctico institucionalizado en los procedimientos legislativos, ya que el juez, en el Estado social al poner en relación la Constitución -sus principios y sus normas- con la ley y con los hechos hace uso de una discrecionalidad interpretativa que necesariamente limita el sentido político de los textos constitucionales, negando incluso, su carácter cualitativo y consensual. Dicho de otra manera, un sistema jurídico no es válido y legitimo solo porque en un determinado momento la mayoría de la población cree que es, sino que dicha creencia se debe fundar en argumentos, configurándose de esta manera una especie de "principio discursivo" regulador de la conducta del sujeto. Principios que deben representar los intereses de todos los afectados, pero sobre todo, deben gozar de la aceptabilidad necesaria para poder definir su legitimidad; es así como la norma;

"Lejos de regular los intereses que se enfrentan, la norma expresa lo que resulta de una confrontación, siempre argumentativa, de los intereses. Es el procedimiento argumentativo el que autoriza el paso del interés expresado al interés fundado, del hecho al derecho, es decir, la transformación de los intereses en normas." (Ferry 2001, 62).

El escenario planteado, que se presenta de manera formal e informal en nuestra vida cotidiana, cuando surgen conflictos de distinta naturaleza sobre una determinada norma valida dentro de un colectivo social; en la que, el procedimiento discursivo y argumentativo hace posible develar o hacer explícito, las pretensiones de validez, que se encuentran implícitas en la norma objeto de litigio. En esto consiste, la importancia del procedimiento discursivo, por cuanto, permite establecer los acuerdos necesarios que contribuyen a la legitimidad de las normas.

Esta idea, ancla sus raíces en la postura crítica que entiende que el principio democrático es el que permite la validez y legitimidad de las instituciones estatales, ya que en cierto sentido, facilita una ordenación de 
la vida social en el que la titularidad de la soberanía corresponde a las generaciones vivas que hacen uso estratégico de emisiones perlocutivas para la producción de efectos en los receptores con pretensiones de validez, por consiguiente, las relaciones entre gobernantes y gobernados están reguladas de modo tal que éstos disponen de unos ámbitos reales de libertad que les permiten el control efectivo de los titulares ocasionales del poder. Este sistema se mueve por una lógica del poder que en opinión de Habermas: "es el derecho el que le confiere forma jurídica, el que le confiere un carácter obligatorio, y a la vez, de quien deriva la obligatoriedad. (...) Desde la perspectiva del derecho, tanto la política como las leyes y disposiciones exigen una fundamentación normativa" (Habermas 1988, 49).

En estos términos Juan Carlos Velasco anota que "el principio discursivo" es válido para el conjunto de cuestiones prácticas, tanto en la esfera moral como en la esfera jurídica (Velasco 2013, 77), con ello se genera una especie de complementariedad entre derecho y moral. Lo que en palabras de Habermas equivale a decir que "la moral autónoma y el derecho positivo, remitido estructuralmente este último a la necesidad de justificarse, guardan más bien entre sí una relación de complementariedad" (Habermas 2008, 171).

\section{Derecho y moral en Jürgen Habermas}

Es necesario hacer una mirada sobre la concepción sociológica del derecho, al igual que la concepción filosófica sobre la justicia que tiene la teoría de Habermas y que se encuentran planteadas en su obra Facticidad y Validez. Con la intención de mostrar el papel no solo funcional del derecho en la sociedad, sino su función de integración social. Esta función integradora del derecho en la sociedad, se ha venido realizando de manera marginal; es decir, en las sociedades modernas de naturaleza compleja, en las que existen otros factores distintos al derecho y que cumplen igualmente un papel de regulación social; nos referimos por ejemplo al dinero, al poder $\mathrm{y}$ al poder administrativo. En este sentido se señala:

"Que existe una objeción más radical, a saber, en la objeción de que un derecho que se ha vuelto periférico no tiene más remedio que 
despojarse cada vez más incluso de la apariencia de normatividad, si es que quiere seguir cumpliendo sus funciones en vistas de la creciente complejidad de la sociedad." (Habermas 2008, 106).

Si se partiera, de que esta afirmación es cierta, considera Habermas,

"Esta afirmación, si estuviese en lo cierto, privaría de su suelo a una teoría discursiva, como es la nuestra, que conecta con la autocomprensión normativa del derecho; ese planteamiento nuestro habría perdido entonces de antemano el contacto con la realidad que se habría vuelto cínica." (Habermas 2008, 106).

Frente al escepticismo que suscita la dinámica normativa del derecho, como mecanismo de integración y cohesión social que será objeto de estudio y discusión en las ciencias sociales. Es aquí, donde surgen las teorías filosóficas sobre la justicia, que permiten construir principios racionales del derecho, sobre los cuales, se tratan de construir formas de organización social mucho más integradas y organizadas. Precisamente, aquí radica uno de los problemas de la teoría del derecho de Habermas, por cuanto, existen muchas dificultades en las sociedades modernas para construir estos principios racionales del derecho, sobre la cual, debe instituirse una sociedad más organizada.

Tratemos a continuación, de abordar esta línea de discusión sobre teoría del derecho, tratando de mostrar los pros y los contras de dicha teoría y los inconvenientes a los que se ve enfrentado un discurso filosófico sobre la justicia desarrollada de manera normativa. En este sentido, una sociedad bien ordenada se entiende, como aquella que está construida y soportada de acuerdo a un orden jurídico racional. Desde estos principios racionales, se construye un tipo de sociedad fundada sobre la base del contrato social; que va ser un modelo de sociedad propio de los Estados liberales. Es así, como:

"La intención de construir en términos de derecho natural racional las instituciones básicas del orden social vienen a parar en todas las teorías contractualistas en que la sociedad queda entendida en conjunto 
como un producto intencional resultante de la asociación voluntaria de miembros que originalmente son autónomos y libres." (Habermas 2008, 107)

Esta asociación autónoma y libre de los miembros de una sociedad; permite el surgimiento de la sociedad civil moderna, como un actor dentro del engranaje del orden social. Es inobjetable, cuando hablamos de una sociedad compleja, no aludir al papel de la sociedad civil como un actor integrado al orden social; concepto que ha sido entendido de muchas formas:

\begin{abstract}
"Adam Smith y Ricardo entienden la sociedad civil como una esfera de tráfico de mercancías y de trabajo social, dominada por legiformidades de tipo anónimo. Hegel, siguiendo la económica política, da a esa sociedad el nombre de $<<$ sistema de necesidades $>>$, sistema en el que los individuos están privados de toda libertad real. Y finalmente, Marx, reconoce en la anatomía de la sociedad civil estructuras económicas que discurren por encima de la cabeza de los individuos que se alienan de sí mismo, produciendo formas dramáticas de desigualdad social." (Habermas 2008, 108)
\end{abstract}

Como se puede constatar, la anatomía de la sociedad civil, la forma como es definida desde el punto de vista de la economía política, tienen la función de desentrañar y develar; "no son las relaciones jurídicas, sino las relaciones de producción, las que constituyen el armazón óseo que sostiene al organismo social" (Habermas 2008, 109). En este sentido, se concibe la sociedad civil, desde los postulados de la economía política, como el terreno donde se desarrollan los conflictos sociales; que son generados por las dinámicas económicas de dominación; conflictos generados por el acceso a los medios de producción. Con este postulado, se crea una concepción sobre la teoría social, que estará marcada y definida por las fuerzas del mercado. La teoría de la sociedad no es ya, el fruto de acción intencional, libre y autónoma de los miembros de una sociedad, que se ponen de acuerdo de manera racional sobre la mejor forma de organizar la sociedad, desde el punto de vista normativo y 
jurídico. En consecuencia; "La unidad manifiesta de un orden estatal jurídicamente constituido queda ahora sustituida por la unidad latente, sistemáticamente producida, del proceso económico global de autorrealización del capital" (Habermas 2008, 109). Este será uno de los asuntos, que los principios de una razón comunicativa deben abocar, con la intención de generar procesos de integración social que permitan que los miembros de una sociedad se pongan de acuerdo sobre asuntos normativos y principios jurídicos que deben ser institucionalizados; no solo en lo discursivo, sino en las instituciones sociales, sobre la cual se deben organizar las sociedades modernas. De aquí, nace una de las razones esenciales del derecho en las sociedades modernas; y es que se convierte en un factor de cohesión social, que hace posible una forma de organización social racional e integrada.

Lo anterior, es pertinente en el contexto de lo que venimos planteando, de sociedades marcados por una fuerte proceso económicos que absorben los proceso de sociación y socialización, y que en términos de Habermas "deshace como mera apariencia aquella supuesta $<<$ integración social $>>$ efectuada a través de valores, normas y procesos de entendimiento, $y$, por tanto, también la que discurre a través del derecho" (Habermas 2008, 110). Con ello, las sociedades siguen un curso que desborda la lógica de la historia, marcada por las dinámicas dialécticas de los mismos procesos sociales; dejándose absorber por las dinámicas de la acumulación de capital, que terminan cosificando todas las esferas del mundo de la vida; creando un tipo de sociedad atomizada e indiferente a sus propias realidades.

El funcionamiento social visto desde la óptica de la teoría de sistemas; muestra una sociedad compleja en su funcionamiento y organización, por cuanto, el orden social se estructura de manera funcionalista, descentrada y diferenciada; constituida por subsistemas de poder, que se auto regulan por sí mismo de forma autónoma e independiente; sin interferir en el funcionamiento de los demás subsistemas. En esto consiste precisamente la teoría de sistemas de N. Luhmann, el cual se presenta "como el sucesor de la fenomenología trascendental por el lado de la teoría de sistemas, dando de ese modo un giro a la filosofía del sujeto y asentándola sobre un objetivo radical" (Habermas 2008, 110). 
En este contexto, de la existencia de sociedades complejas, vistas desde la teoría sistémica de N. Luhmann, que se convierte en una especie de paradigma, al momento de hacer un análisis sociológico de la sociedad; lo cual nos genera la pregunta sobre el sistema jurídico; en el sentido de qué papel juega el sistema jurídico en una sociedad compleja; en consecuencia,

"El sistema jurídico -o las estructuras que en él subyacen- recobran una parte de la autonomía que, por así decir, la crítica ideológica les había hecho perder. El derecho ya no se considera como epifenómeno, sino que vuelve a cobrar un sentido propio y especifico. Sin embargo, en una sociedad integralmente descentrada sigue ocupando no más que una posición periférica, constituye un sistema o un discurso dentro de una pluralidad desordenada de sistemas y discursos." (Habermas 2008, 111)

Hagamos una mirada a la teoría sociológica del derecho de Niklas Luhmann; tratando de entender, porque le dan una posición marginal y objetivista a la validez del derecho. Para iniciar es necesario señalar que en esta teoría.

"El derecho se entiende únicamente desde el punto de vista funcional de la estabilización de expectativas de comportamiento. En las sociedades funcionalmente diferenciadas el derecho se especializa en generalizar concordantemente expectativas en las dimensiones temporal, social, y objetiva, de suerte que en los casos de conflicto que contingentemente surjan pueda decidirse vinculantemente conforme al código binario $<<$ justo $>>$ jurídico/ <<injusto $>>$ jurídico." (Habermas 2008, 112)

Por ello, nos referimos a la minimización funcional del derecho por parte de la teoría de Luhmann; Lo cual tendrá los siguientes efectos en el análisis social; Primero, reduce el sistema jurídico, a una función de control social en términos de lo justo e injusto; convirtiendo al sistema jurídico en un subsistema de poder autónomo, pero cerrado, totalmente desligado de los otros subsistemas. De esta forma, 
"la desconexión entre un sistema jurídico monádicamente cerrado a la vez que monádicamente abierto y el resto de los subsistemas de acción. Ese sistema jurídico que se ha vuelto autónomo ya no puede mantener un intercambio directo con su entorno interno a la sociedad, ni tampoco obra regulativamente sobre ellos" (Habermas 2008, 112), por eso, se minimiza la función del derecho, a una labor de regulación y control social, que hace que el derecho se cierre, se aislé y se presente como marginal a los otros subsistemas de acción característica de una sociedad compleja: Ahora bien, es por medio de la acción reguladora y de control que ejerce el derecho; con la que es posible mantener el orden e integración social. La pregunta que nos planteamos es, ese es el único mecanismo posible para garantizar la cohesión en las sociedades complejas; podríamos responder que sí, porque efectivamente así funciona el derecho, lo importante es precisar que tan efectiva $\mathrm{y}$ valida es este proceso de regulación y control, es decir, que tan legítimo y aceptable es por los miembro de una sociedad. Precisamente aquí, tiene sentido, hablar de los principios de racionalidad comunicativa y los principios procedimentales de la ética discursiva. Dichos principios hacen posible la construcción normativa, valida y legitima de las normas que en un sistema jurídico; deben aplicar para garantizar el control y el orden social.

De esta forma, queda evidenciado el papel funcionalista del derecho, que defiende Luhmann en su teoría de sistemas; reduciéndolo a una función solamente de aplicación; dándole con ello, un rol mínimo y marginal; pero obviamente útil, en cuanto a su función reguladora y de control social. En síntesis, podemos decir,

"La objetivación del derecho que lo convierte en un sistema autoregulado. Bajo esta descripción la comunicación que se efectúa a través del código binario $<<$ justo $>>$ jurídico/<<injusto $>>$ jurídico queda privada del sentido que tiene para la integración social. Con ello las normas jurídicas y las acciones jurídicas pierden toda conexión con la suposición de procesos de entendimiento racionalmente motivados de los miembros que constituyen la comunidad jurídica." (Habermas 2008, 114) 
Entonces, el papel del derecho, como ya señalamos anteriormente, queda reducido a una función de regulación social; que se lleva a cabo, por medio de la resolución de conflictos que se presentan en la vida social. De esta forma, las argumentaciones jurídicas en una teoría de sistemas, quedan reducidas a simple comunicaciones especiales; que consisten en palabras de Luhmann,

"Las razones ya no disponen de la fuerza intrínseca de motivar racionalmente, si las razones, como reza la fórmula de Luhmann, no pueden razonarse, esa cultura de la argumentación, desarrollada con tanto trabajo, solicitud y empeño en el sistema jurídico, se convierte en un enigma. Habría que explicar por qué $<<$ se necesitan razones que no son en absoluto razones $>>$."(Habermas 2008, 114)

Finalmente, tenemos que decir, que la teoría de sistemas "liquida los últimos restos del normativismo del derecho natural racional. El derecho se reduce a un sistema autopoiético, despojándolo de todas sus connotaciones normativas" (Habermas 2008, 115) En consecuencia, la validez del derecho, se deriva de las mismas normas jurídicas vigentes y positivizadas; totalmente desarticuladas de las relaciones con su entorno; es decir, es la puesta en práctica de la validez del derecho positivo, donde su legitimidad se deriva de sí mismo.

Podemos decir, que este escenario de fragmentación, donde cada uno de los subsistemas constitutivos de una sociedad compleja, actúa de manera autónoma e independiente y se regulan a sí mismas, en el engranaje social; sin ningún tipo de vínculo e interrelación comunicativa con los otros subsistemas; generando con ello, el funcionamiento de un orden social no integrado. En consecuencia, hablar de una teoría de la sociedad en términos de integración, implica hacer posible la generación de vínculos sociales de naturaleza comunicativa que permita que los miembros de una sociedad se pongan de acuerdo sobre asuntos normativos, asuntos morales, asuntos de justicia y de vida buena. Lo anterior, es posible a través del uso de una concepción de racionalidad comunicativa que pueda usarse en los escenarios prácticos y de la vida cotidiana. 


\section{Concepto de política deliberativa en Habermas}

A continuación, y siguiendo con la teoría política de Habermas, es imperioso hacer referencia al concepto de política deliberativa; a través del cual, se desarrollar un concepto procedimental de democracia, haciendo énfasis en una razón comunicativa; el papel de la sociedad civil y del espacio público político. Es en el terreno de la política deliberativa donde se pretende poner en práctica el procedimiento formal de la ética del discurso; que a través del ejercicio deliberativo y argumentativo se puedan construir los acuerdos políticos que gocen de validez y legitimidad por parte de los involucrados.

Para este ejercicio Habermas, parte de una concepción de democracia en términos empiristas; sobre la cual se construye una idea de legitimidad democrática, que a su vez se enmarca en unos modelos normativos de democracia. En este escenario democrático, los sujetos interactúan sus concepciones de vida buena y de vida justa. Es por ello, "que la relación constitutiva entre el poder y el derecho cobra relevancia empírica a través de las presuposiciones conceptualmente inevitables de la producción legítima de normas y a través de la institucionalización de la correspondiente práctica de autodeterminación de los ciudadanos" (Habermas 2008, 365) Estas teorías del poder empiristas, no desconocen la influencia normativa del poder político, que se ubica en el nivel del poder social, de esta forma;

"Según una lectura, el $<<$ poder social $>>$ se expresa en la capacidad que tienen de imponerse intereses superiores que pueden ser perseguidos de forma más o menos racional; el $<<$ poder político $>>$ puede concebirse entonces como una forma abstraída de poder social, articulada de forma estable, que permite intervenciones sobre el $<<$ poder administrativo >>."(Habermas 2008, 365)

Lo anterior significa, que el ejercicio del poder político, se enmarca en un contexto organizado y regulado en el que se puede ejercer; en este sentido Habermas considera: 
"Desde la perspectiva empirista del observador la pretensión de legitimidad del derecho, que se transmite al poder político a través de su forma jurídica, al igual que la necesidad de legitimación que puede cubrirse recurriendo a determinados criterios de validez, caen bajo la descripción distintas que desde la perspectiva del participante: las condiciones de aceptabilidad del derecho y del poder político se transforman en condiciones de $<<$ aceptancia $>>$ y las condiciones de legitimidad se transforman en condiciones de estabilidad de una fe en la legitimidad de la dominación, fe que por término medio correspondería a toda la comunidad jurídica." (Habermas 2008, 365)

Estos principios democráticos; esenciales de una sociedad liberal que se fundan sobre la aceptancia y legitimidad del orden político y jurídico, son los que garantizan la estabilidad de un orden social. En esta forma se construye una teoría de la democracia, que tiene como propósito que los ciudadanos participen de forma deliberativa en la construcción de normas validas, que garanticen la validez y legitimidad del grupo social. De tal forma, que son los ciudadanos de manera participativa, quienes se involucran en los debates públicos alrededor de temas o problemas que requieren de la aquiescencia de todos los afectados; y con ello, las reglas empíricas de la democracia gozaría de aplicación práctica y útil. Para que estas reglas empíricas de la democracia operen, se necesita que exista un modelo de democracia que las haga viables. En consecuencia Becker, reflexiona diciendo:

"Así como el poder se expresa en la superioridad empírica del interés o la voluntad más fuerte, así también el poder estatal se expresa en la estabilidad del orden que logra mantener. La legitimidad se considera medida de la estabilidad, pues objetivamente la legitimidad del Estado se mide por el reconocimiento fáctico de que es objeto por parte de los sometidos a la dominación." (Habermas 2008, 366)

Como podemos apreciar, la estabilidad de un orden social se funda en la legitimidad que se construye entre los ciudadanos frente a sus instituciones; ese reconocimiento hace posible la estabilidad de un orden social; ahora bien, como se construye esa estabilidad; podemos decir, que existen 
dos vías para ello, una la resignación; entendida como el reconocimiento, acatamiento y/o obediencia a un poder instituido y la otra vía es el libre reconocimiento del poder instituido. Pero frente a este asunto Becker señala:

"Una legitimación es tan buena como cualquier otra, con tal que contribuya lo suficiente a la estabilización de la dominación. Según esto, también una dictadura puede considerarse legítima mientras el marco legitimatorio socialmente reconocido posibilite la estabilidad del estado. Desde el punto de vista de la teoría del poder la calidad de las razones carece de relevancia empírica: <<es una equivocación de los liberales y demócratas creer que las dictaduras sólo pueden sobrevivir bajo la "protección de las bayonetas'"' (Habermas 2008, 366)

De esta forma, se puede interpretar la estabilidad y legitimidad de un orden democrático; donde la estabilidad estaría determinada por el reconocimiento y aceptancia por parte de los ciudadanos de una forma de poder político; que como hemos señalado anteriormente, se puede aceptar por resignación o por el libre asentimiento; y en ambos caso queda abierta la discusión para entender otras formas de ejercer el poder político que garantice tal estabilidad y reconocimiento y una de esas formas son las dictaduras o cualquier forma de ejercer el poder político, por fuera de los causes de los principios democráticos. Principios democráticos que se ejercen desde la deliberación pública, el principio de las mayorías, y la competencia entre partidos políticos.

Luego entonces, para comprender la libertad, desde una visión empirista, hay que tener en claro que;

"En una lectura empirista la comprensión moderna de la libertad significa entre otras cosas que $<<$ la validez de las normas que el hombre particular acepta, viene generada por él mismo a través de su libre asentimiento. A esta comprensión voluntarista de la validez responde una comprensión positivista del derecho: como derecho se considera aquello y sólo aquello que un legislador político, elegido conforme a los criterios establecidos, establece como derecho." (Habermas 2008, 367-368) 
Las reglas practicas aportadas por los principio democráticos propios de una sociedad liberal; los que permiten establecer reglas de juego democrática, a partir de las cuales, se establecen e institucionalizan escenarios de poder que están facultados para producir las normas jurídicas que se requieren para regular y garantizar el funcionamiento social; para el caso particular estaríamos hablando del congreso o del parlamento que serían los escenarios constitucionales donde se producen las normas jurídicas que gozan del asentimiento de los ciudadanos. De esta manera en una sociedad democrática, es aquella; "en la que ciudadanos racionales, no tendrían, bajo una autodescripción empirista de sus prácticas, razón suficiente para respetar las reglas de juego democrático" (Habermas 2008, 371). Todo lo anterior, nos conduce a hablar de los modelos normativos de democracia; a los que nos hemos referido con anterioridad.

En consecuencia la dinámica en una sociedad liberal, el proceso democrático, se llevan a cabo en medio de intereses particulares, sobre los cuales los individuos se ponen de acuerdo, alrededor de dichos intereses. Por su parte en la concepción republicana, la formación democrática es el resultado de procesos de auto entendimiento de naturaleza ética y política. Hasta aquí, podemos distinguir las concepciones de ambos modelos de democracia y sus implicaciones en la formación democrática; pero es necesario precisar, el papel que juega la teoría del discurso en el terreno de estas concepciones normativas de democracia. Según Habermas:

"La teoría del discurso toma elementos de ambos lados y los integra en el concepto de un procedimiento ideal para la deliberación y la toma de decisiones. Este procedimiento democrático establece una conexión interna entre las consideraciones pragmáticas, los compromisos, los discursos de auto entendimiento y los discursos relativos a justicia y fundamenta la presunción de que bajo las condiciones de un suficiente suministro de información relativa a los problemas de que se trate y de una elaboración de esa información, ajustada a la realidad de esos problemas, se consiguen resultados racionales, o, respectivamente, resultados fair." (Habermas 2008, 372) 
De esta forma se definen unas reglas propias del discurso y la argumentación que tienen como propósito generar el proceso de entendimiento y construcción de acuerdos, que posibiliten el ejercicio comunicativo y deliberativo; con ello, estaríamos hablando de un concepto de democracia que es resultado de un proceso de auto entendimiento y auto organización de la sociedad, por medios discursivos. Pero qué efecto tiene para la sociedad esta concepción sobre la política y la democracia, "La consecuencia de ello es una concepción de la política, polémicamente dirigida contra el aparato estatal" (Habermas 2008, 373).

En este sentido, el modelo republicano permite la autoorganización de la sociedad, por medios deliberativos, donde se generan los proceso de entendimiento; de tal forma que se revitaliza el espacio público social en términos de sociedad civil organizada, que en su accionar se convierte en un poder no solo de deliberación, sino de incidencia frente al estado; de tal manera que la sociedad civil organizada se convierte en; "La sociedad civil, en tanto que base social de los espacios públicos autónomos, se distingue tanto del sistema económico como de la administración pública". (Habermas 2008, 375)

Como se puede notar, la teoría del discurso tributa al proceso democrático, aspectos normativos, que permite articularlos de manera novedosa; de tal forma que:

"El desarrollo y consolidación de una política deliberativa, la teoría del discurso los hace depender, no de una ciudadanía colectivamente capaz de acción, sino de la institucionalización de los correspondientes procedimientos y presupuestos comunicativos, así como de la interacción de deliberaciones institucionalizadas con opiniones públicas desarrolladas formalmente." (Habermas 2008, 374)

Con ello, la teoría discursiva y su carácter intersubjetivo, permite la generación de los proceso de diálogo, entendimiento y acuerdos entre los ciudadanos, a través de las reglas democráticas, procedimentales o formales que se requieren en todo proceso deliberativo; que para el caso de una sociedad democrática debe trascender al ámbito de la esfera pública social; de ahí, el carácter democrático de la teoría discursiva. De tal forma que: 
"Con la teoría del discurso entra de nuevo en juego una idea distinta: Los procedimientos y presupuestos comunicativos de la formación democrática de la opinión y la voluntad funcionan como importantísima esclusa para la racionalización discursiva de las decisiones de una administración y un gobierno ligado al derecho y a la ley.' (Habermas 2008, 376)

Lo anterior, corrobora aún más, la tesis que hemos venido defendiendo alrededor de los procesos discursivos y formales, que llevados al ámbito de la deliberación política y jurídica permiten generar proceso de entendimiento y acuerdos, que le dan estabilidad, gobernabilidad y legitimidad a un orden social. Además, de ser factores incluyentes en los proceso de integración social y construcción de una forma de poder moderno, que estarán direccionadas por la opinión pública; y con relación a este asunto de la opinión pública, el profesor Habermas manifiesta;

"Es un subsistema especializado en la toma de decisiones colectivamente vinculante, mientras que las estructuras comunicativas de la opinión pública constituyen una vasta red de sensores que reaccionan a la presión de problemas o situaciones problemáticas que afectan a la sociedad global, y estimulan opiniones influyentes. La opinión pública así elaborada y transformada (conforme a procedimientos democráticos) en poder comunicativo no puede ella misma $<<$ mandar $>>$, sino sólo dirigir el uso del poder administrativo en una determinada dirección." (Habermas 2008, 376)

La idea de sociedad civil como poder, que incide en las decisiones del poder administrativo, en el que se muestra el poder que tiene la opinión pública cuando logra definir acuerdos que involucren al mayor número de personas; a esto precisamente es lo que denominamos política deliberativa; o mejor, para expresarlo en otros términos; como una concepción de política deliberativa, hace posible una concepción de poder en términos de opinión pública; es decir de una ciudadanía que haciendo uso de los principios democráticos, informada, organizada y con argumentos es capaz de incidir en la esfera pública y en el poder administrativo; Haciendo de la democracia un hecho real. 
Frente a lo anterior, es pertinente mencionar una reflexión del profesor Norberto Bobbio y citada por Habermas, en los siguientes términos:

\begin{abstract}
"Empieza registrando algunos cambios sociales globales, que no vienen precisamente a facilitar el desempeño de la promesa de las concepciones clásicas: sobre todo, el surgimiento de una sociedad policéntrica de grandes organizaciones, en la que la influencia y el poder político pasan a actores colectivos y cada vez pueden ser menos adquiridos y ejercidos por los individuos asociados; también la multiplicación de grupos de interés que compiten entre sí, que dificultan una formación imparcial de la voluntad, el extrañamiento de las masas apáticas respecto de las élites, las cuales se autonomizan oligárquicamente frente a unos ciudadanos tratados en términos paternalistas."(Habermas 2008, 379)
\end{abstract}

Lo anterior, configura un escenario social y político mucho más complejo para el ejercicio de la ciudadanía y la participación política de los ciudadanos. Pero además, Bobbio establece unas reglas mínimas de funcionamiento de un sistema democrático; reglas que se definen como mínimas, en ese sentido señala, " $<<$ Doy por sentado que el único modo de entenderse cuando se habla de democracia, en cuanto algo contrapuesto a toda forma de gobierno autocrático, es el considerarla caracterizada por un conjunto de reglas... que establecen quién está autorizado a tomar las decisiones colectivas y con qué procedimientos $>>$ " (Habermas 2008, 38) Y son estas reglas mínimas que permanecen en las dinámicas democráticas occidentales, las que llevan a Bobbio a la siguiente tesis:

"El contenido mínimo del Estado democrático no se ha deteriorado: garantía de los principales derechos de libertad, existencia de varios partidos en competencia entre sí, elecciones periódicas mediante sufragio universal, decisiones colectivas o pactadas o tomadas sobre la base del principio de la mayoría; y en todo caso siempre tras un libre debate entre las partes o entre los aliados de una coalición gubernamental." (Habermas 2008, 380) 
Esta teorización sobre la democracia, que plantea el profesor Bobbio no acaba la teoría reconstructiva del derecho que hemos venido realizando desde la teoría discursiva, en el sentido, que si bien es cierto, la existencia de un sistema democrático requiere de unas reglas procedimentales mínimas que permitan su funcionamiento; igualmente los acuerdos que se construya por medio de la puesta en prácticas de esas reglas formales, debe ser institucionalizados. La puesta en prácticas de esas reglas mínimas, que permitan el ejercicio del debate público, las deliberaciones y las controversias partidistas e ideológicas, deben traducirse en acuerdo que se acatan e institucionalizan; por cuanto del respeto de esos acuerdo depende el orden y la tranquilidad no solo política, sino social y en especial del orden democrático que debe ser preservado. Dentro de esas reglas mininas, que deben ser acatadas en un sistema democrático; encontramos el principio de las mayorías. Por consiguiente, Habermas considera; "el quid de esa comprensión radica en que el procedimiento democrático institucionaliza discursos y negociaciones con ayuda de formas de comunicación que, para todos los resultados obtenidos conforme al procedimiento, habría de fundar la presunción de racionalidad". (Habermas 2008, 380) Pero además, este principio de las mayorías ha tenido observaciones contrarias; como es el caso de la expuesta por John Dewey, quien señala;

"La regla de la mayoría, justo como regla de la mayoría, es tan tonta como sus críticos dicen que es. Pero nunca es simplemente la regla de la mayoría... Los medios por los que una mayoría llega a ser una mayoría es aquí lo importante: debates previos, modificaciones de los propios puntos de vista para hacer frente a las opiniones minoritarias... La necesidad esencial, en otras palabras, es la mejora de los métodos y condiciones del debate, de la discusión y la persuasión." (Habermas 2008, 380-381)

En el terreno del debate público y democrático, tiene sentido la existencia de un concepto de política deliberativa, y la necesidad de la deliberación pública, que permita formar una ciudadanía deliberante, involucrada en los asuntos públicos, a través del discurso y la 
argumentación. Por ello, es necesario hablar de una reglas de juego en el debate público, vale decir, un procedimiento formar discursivo que permita que los sujetos no solo se involucren en estos debates públicos, sino que tengan derecho a participar con sus argumentos.

Del procedimiento anteriormente planteado, se deriva la legitimidad de las decisiones lograda; como resultado de un ejercicio político de carácter público, en la que los involucrados se ponen de acuerdo sobre ciertos asuntos y se someten a ellos. Ahora bien, como funciona este procedimiento democrático, de acuerdo con Cohen; mediante el siguiente procedimiento:

“(a) Las deliberaciones se efectúan en forma argumentativa, es decir, mediante el intercambio regulado de informaciones y razones entre partes que hacen propuestas y las someten a crítica. (b) Las deliberaciones son $<<$ inclusivas $>>$ y públicas. En principio no puede excluirse a nadie; todos los que puedan verse afectados por las resoluciones han de tener la mismas oportunidades de acceso y participación. (c) Las deliberaciones están exentas de coerciones externas. Los participantes son soberanos en la medida en que sólo están ligados a los presupuestos comunicativos y reglas procedimentales de la argumentación. (d) Las deliberaciones están exentas de coerciones internas que puedan mermar la igual posición de los participantes. Todos tienen la misma oportunidad de ser escuchados, de introducir temas, de hacer contribuciones, de hacer propuestas y de criticarlas. Las posturas de afirmación o negación vienen sólo motivadas por la coerción sin coerciones del mejor argumento." (Habermas 2008, 382)

\section{Conclusiones}

En este procedimiento se expresan los elementos formales de la teoría discursiva, que permite la puesta en práctica de un concepto de democracia deliberativa; que para ser prácticos y reales deben institucionalizarse, es decir, que una cultura los haga propio; como forma y mecanismo de resolver los temas en litigio, hacer posible la valides sobre concepciones del mundo y sobre toda viabilizar un concepto de 
legitimidad que se haga practico en las formas de vida cotidiana. Alrededor de este concepto de democracia deliberativa, se tejen concepciones y enfoque distintos como son: el enfoque liberal, el republicano y el comunitarista.

Todos estos enfoques, apuntaran a la necesidad de una teoría del discurso y a unos procedimientos comunicativos que permitan la puesta en práctica de una racionalidad comunicativa; tanto en el terreno de las normas morales, como en las jurídicas y políticas; de ahí se desprende lo que hemos venido desarrollando y es la construcción de una teoría de la moralidad y la legitimidad política. Se requiere, entonces en las democracias modernas, la existencia de un concepto de la política como deliberación pública; que haga posible que las pluralidades y los descensos sobre el mundo de la vida se expresen racionalmente, vale decir a través de argumentos que posibiliten el entendimiento y los acuerdos que garanticen un orden social regulado y estable.

\section{Bibliografía}

Aguilò, J. (2000)Teoría general de las fuentes del derecho y del orden jurídico. Barcelona: Ariel.

Alexy, R. (2012) Teoría de la argumentación jurídica. 2a edición. Madrid: Centro de estudios Políticos y Constitucionales.

Austin, J. (1981) Como hacer cosas con palabras. Barcelona: Paidòs.

Cachumbè, N. (2004) "Acción comunicativa, derecho y organización social y el concepto de derecho en Habermas." Criterio Jurídico.

Ferry, J. M. (2001) La ética reconstructiva. Santafé de Bogotá: Siglo del hombre editores.

Ghersi, E. (2007) El carácter competitivo de las fuentes del derecho. Lima: Universidad Francisco Marroquin.

Habermas, J. (2008) Facticidad y Validez. Madrid: Trotta.

Habermas, J. (1988) Teoría de la acción comunicativa. Madrid: Taurus.

Habermas, J. (1995) Problemas de legitimación en el Capitalismo tardío. Buenos Aires: Amorrortu.

Velasco, J. C. (2003) Para leer a Habermas. Madrid: Alianza. 